\title{
System for ampacity monitoring and low sag overhead conductor evaluation
}

\author{
E. Fernandez \\ I. Albizu \\ M.T. Bedialauneta \\ S. de Arriba \\ A.J. Mazón \\ Department of Electrical Engineering \\ University of the Basque Country (UPV/EHU) \\ Bilbao, Spain \\ elvira.fernandezh@ehu.es igor.albizu@ehu.es miren.bedialauneta@ehu.es sdearrib@hotmail.com javier.mazon@ehu.es
}

\begin{abstract}
Among the different alternatives to achieve the uprating and better use of existing overhead power lines are the use of high temperature low sag conductors and the use of real time monitoring systems for knowing the ampacity of the lines. So far, the uprating of a power line through both alternatives have been considered separately. However, it is possible to combine both solutions and obtain greater benefit in terms of achievable uprating, and a better control of the reliability of the conductor. This paper presents a system for monitoring the ampacity and for the evaluation of the low sag behavior of the overhead power lines. This system allows knowing the power flow of the lines in order to optimize their use and evaluating the conductor monitored in order to validate their behavior in operating condition.
\end{abstract}

\section{INTRODUCTION}

The power transmitted in both transmission and distribution electrical lines has increased considerably over the past twenty years. As a result of the increased power flow, some lines can be close to their ampacity limit. The ampacity or thermal rating is that current which will meet the design, security and safety criteria of a particular line. So, it is important to maintain the flow of the lines below its ampacity limit. The conductor temperature depends on the current value and weather magnitudes. An increase in the conductor temperature produces an elongation of the conductor. This elongation can be dangerous for the reduction of the distance between the conductor and the ground or other lines that cross under them.

One option to improve the power system could be the installation of new lines. However, the high population density, the intensive use of land and the increasing rejection of new electrical installations determine that a small amount of space is available to be dedicated to electrical lines. Therefore, there is great pressure to increase the power flow in existing right of ways using existing infrastructure as far as possible [1].

As mentioned above, to meet the security and design criteria, the flow of the lines must be lower than its ampacity limit. The ampacity is the current intensity value associated with the maximum allowable temperature of the conductor Generally the maximum allowable temperature is determined by the sag limit but is also restricted by the conductor temperature limit (associated with the loss of mechanical properties) and the temperature limit of clamps and insulators. As the current associated with the maximum allowable temperature depends on weather conditions (speed and direction of wind, ambient temperature and solar radiation), the ampacity is not a constant but also depends on weather conditions.

Traditionally, the ampacity has been calculated assuming high values of ambient temperature and solar radiation and low values of wind speed. It is known as deterministic method of calculating ampacity and represents the worst climatologically conditions that might occur from the point of view of the ampacity. However, most of the time the weather is more favorable and the ampacity value is greater than that obtained from the deterministic approach. In other words, when the current intensity reaches the limiting value obtained from the deterministic approach, normally the conductor temperature is below its maximum allowable temperature. Thus, there is capacity of electrical lines wasted.

The real capacity of electrical lines can be known with real time monitoring systems [2]. These systems allow the determination of line state and the calculation of the actual ampacity value. Ampacity limit is related to conductor temperature and the sag. The conductor temperature must not exceed its maximum allowable temperature and the sag must not exceed the security distance between the conductor and the ground. In fact, both parameters are related, the value of the sag increases when the conductor temperature increases. Thus, the purpose of real time monitoring systems is to assure that the sag limit is not exceeded.

Furthermore, the conductor replacement by high temperature low sag (HTLS) conductors allows increasing the line power flow securely and safely without the need to strengthen the towers. Because of the low sag, these 
conductors reach the sag limit at higher temperatures than the conventional conductors. So, the maximum allowable temperature and the ampacity value are higher [3-4].

So far, the uprating of a line through both alternatives (HTLS conductors or real time monitoring) have been considered separately. However, with the development of new reformulations, it is possible to combine both solutions and obtain greater benefit in terms of achievable uprating, and a better control of the reliability of the conductor.

This paper presents a system for monitoring the ampacity and for the evaluation of the low sag behavior of the overhead power lines. This system allows knowing the power flow of the lines in order to optimize their use and evaluating the conductor monitored in order to validate their behavior in operating conditions.

\section{GENERAL DESCRIPTION OF THE MONITORING SySTEM}

In order to obtain the ampacity of the overhead lines, the monitoring system developed considers the monitoring of the mechanical tension, the ambient temperature, the solar radiation, the wind speed, the current intensity and the conductor temperature.

The system, which includes both hardware implementation and remote control software, allows knowing the maximum current intensity value that can take the monitored line according to the weather conditions and evaluating the conductor behaviour.

The monitoring system developed needs to have some elements in the overhead line and in the control center (Fig $1)$. These elements are general purpose elements that are found easily in the market. Other systems have elements that must be especially designed for the monitoring of the ampacity.

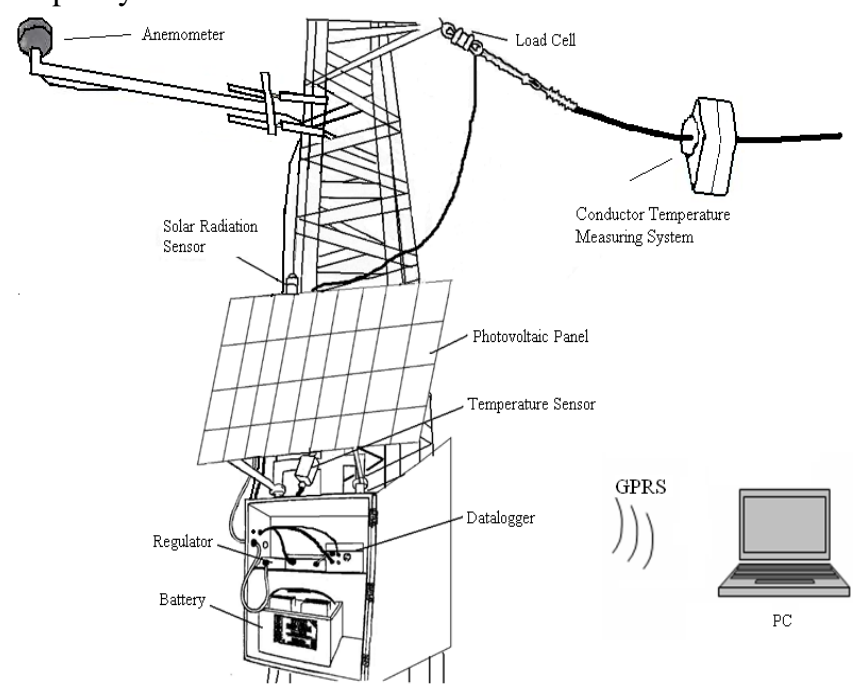

Figure 1. Monitoring system

These elements allow knowing the values needed for the calculation of the ampacity:
- A load cell allows monitoring the value of mechanical tension of the electrical conductor.

- $\quad$ A temperature sensor to measure the temperature.

- A radiation sensor that allows monitoring the solar radiation.

- A current intensity converter that allows monitoring the current intensity of one phase of the overhead line, (it is not shown in Fig. 1 because it is placed at the secondary of a current transformer).

SMT)

A system for measuring the conductor temperature

- $\quad$ An ultrasonic anemometer to measure the speed and direction of the wind.

- Dataloggers that are used for acquiring the data from the sensors and transmitting the data, via GPRS, to the control center.

- A power supply system is needed to provide appropriate power supply for the operation of the sensors and the dataloggers. This system consists of a photovoltaic panel, a regulator and a battery.

Furthermore, as the values measured by the sensors are transmitted via GPRS to a control center, a PC with software for data management and ampacity calculation is required. This software includes the necessary formulation for evaluating the maximum allowable current, from the data measured in the field.

\section{THEORETICAL BEHAVIOUR}

\section{A. Monitoring of ampacity}

The system combines the advantages of the ampacity monitoring systems based on weather magnitudes [5-6], conductor temperature [7-10] and tension [11-13].

The weather monitoring system measures the ambient temperature, the solar radiation and the wind speed. The main drawback is that the conditions, especially the wind, can change along the line due to land irregularities, forests, etc. Hence, there is some uncertainty in the results that can be important in some cases.

The conductor temperature is monitored by a sensor installed in the conductor that measures its surface temperature. Hence, a direct temperature measurement is carried out. The conductor temperature can change along the line due to the change of the weather conditions. The sag is a function of the average temperature whereas the monitoring system gives a local temperature value. Besides, a radial temperature gradient can be present in the conductor. To calculate the ampacity, the weather condition values have to be known. If the current intensity, the ambient temperature and the solar radiation are measured, the equivalent wind velocity that makes the conductor reach the measured conductor temperature can be obtained. These systems, in general, monitor the temperature of the conductor but do not have the value of the tension or the sag. Therefore, they are unable to notice the evolution of the creep and the maximum 
allowable temperature. This limitation can be overcome by measuring the value of the tension or the sag.

The tension is monitored by a load cell that is installed in series with the insulator string. The load cell is located between the tower and the insulator string so that it is electrically insulated from the conductor. As there is a direct relation between the tension and the sag values, the tension monitoring is a good indicator of the line condition when the sag is the magnitude to be controlled. The sag is obtained from the tension value, the span length and the weight per length unit of the conductor. Whereas the conductor temperature measurement is a local measurement, the tension represents the average condition of all the spans between two tension towers. To calculate the ampacity value, the equivalent wind velocity is calculated from the measured tension value. For this purpose, the conductor temperature is calculated previously from the measured tension value. These systems monitor the tension of the conductor, but do not measure the value of the conductor temperature. This limitation can be overcome by adding any element that provides the value of the temperature of the conductor.

\section{B. Conductor evaluation}

Low sag conductors are based on the conductor behavior above the knee-point temperature, where the aluminum is slack and only the core is under tension. This occurs due to the higher coefficient of thermal expansion (CTE) of the aluminum. Hence, above the knee-point temperature the behavior of the conductor is based on the CTE of the core, which is lower than the CTE of the conductor. For this reason, the sag increase with temperature is lower above the kneepoint temperature

The developed monitoring system measures the conductor tension and temperature and it also measures the wind speed to evaluate the conductor load due to wind [14].
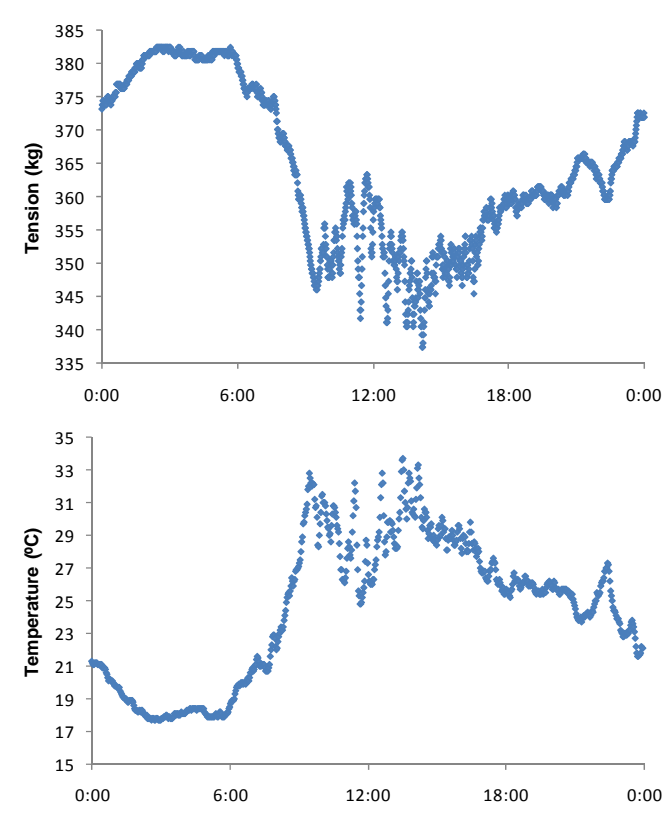

Figure 2. Conductor tension and temperature measured in a line in operation
Figure 2 shows the conductor tension and temperature values measured in a line in operation during a whole day. The direct relation between the tension and the temperature is obvious. The tension value increases when the temperature value decreases and vice versa.

The tension-temperature values that represent the actual behavior of the conductor in operation are obtained processing the acquired measurements. The synchronization of the measurements, the fluctuation of the measurements and the effect of the wind are taken into account.

\section{OPERATIONAL BEHAVIOUR}

\section{A. Monitoring of ampacity}

Using the software developed it is possible to monitor the evolution of the ampacity calculated (Fig. 3). Similarly, the measured and calculated variables are recorded in a database that can be viewed retrospectively in order to discuss different incidents. The calculated ampacity takes into account the uncertainty due to the errors in the temperature estimate [15].

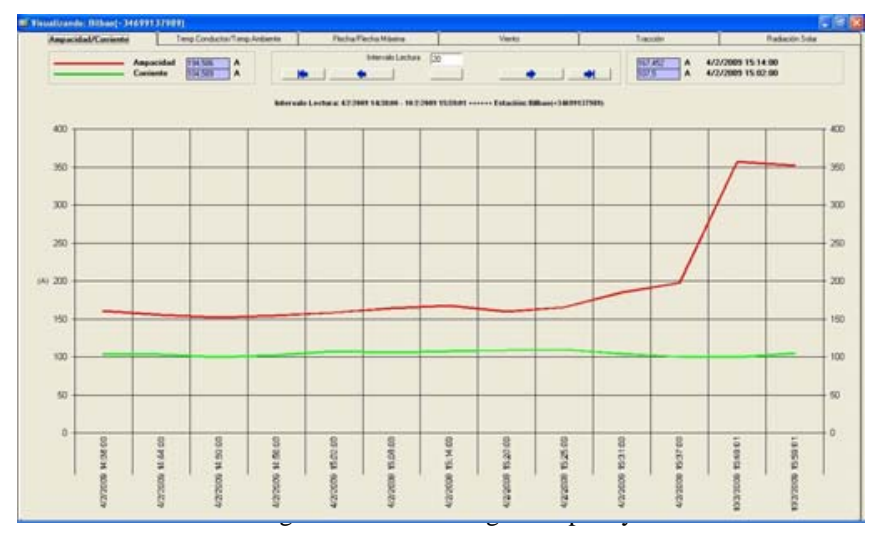

\section{B. Conductor evaluation}

The calculated theoretical tension-temperature curve should represent correctly the actual behavior of the conductor. Thus, the behavior of the core and the aluminum as a function of the elastic modulus and CTE has to be modeled. The knee-point temperature where the aluminum gets slack has to be modeled too. The calculation method used to model the conductor behavior is based in a sagtension method developed by some of the authors taking into account the requirements of the HTLS conductors [16-18].

Figure 4 shows the theoretical tension-temperature curve of the conductor monitored in the presented example (Fig. 2). A correspondence between the theoretical and measured values is observed. However, a larger range of measured values is needed to obtain conclusions of the conductor behavior. 


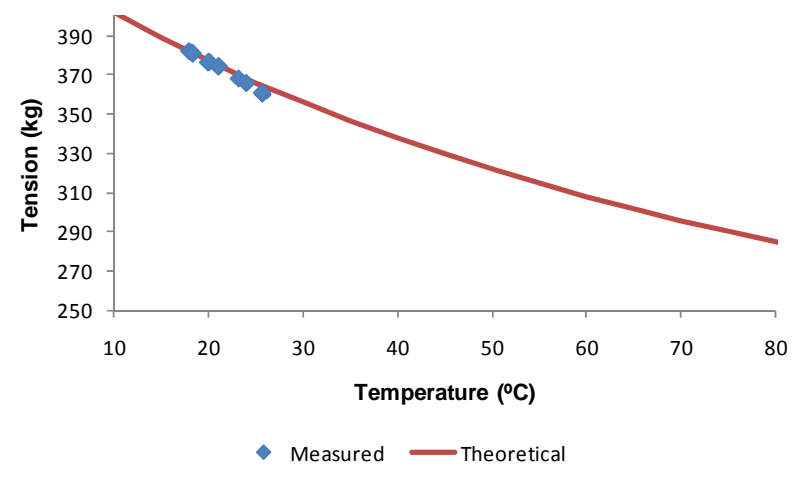

Figure 4. Theoretical and measured tension-temperature values

\section{CONCLUSIONS}

In this paper a system that integrates the ampacity monitoring and the low sag overhead conductor evaluation is presented. This system, which includes both a hardware implementation and remote control software, allows determining the load of the line and evaluating the low sag behavior of the overhead power lines in order to optimize their use.

The system has been developed seeking simplicity (low cost), reliability and accuracy in the ampacity monitoring.

\section{ACKNOWLEDGMENT}

The authors gratefully acknowledge the support of the Iberdrola utility for the help with the achievement of this project.

\section{REFERENCES}

[1] I. Albizu, A. J. Mazon, and I. Zamora, "Methods for increasing the rating of overhead lines”, IEEE PowerTech, St. Petersburg - Russia, 2005.

[2] CIGRÉ 22-12, "Real time monitoring”, ELECTRA, No. 197, pp. 35-47, 2001.

[3] CIGRE Brochure 244, “Conductors for the Uprating of Overhead Lines", 2004.

[4] M. Landeira, P. Morentin, A.J. Mazon, I. Albizu, "The high temperature cable solution for electrical overhead distribution lines", DYNA, Vol. 82, No. 5, pp. 226-230, 2007.

[5] F. Soto, D. Alvira, L. Martín, J. Latorre, J. Lumbreras, M. Wagensberg, "Increasing the capacity of overhead lines in the $400 \mathrm{kV}$ Spanish transmission network: real time thermal ratings”, CIGRÉ Session, 22211, Paris-France, 1998.

[6] H.J. Dräger, D. Hussels, R. Puffer, "Development and implementation of a monitoring-system to increase the capacity of overhead lines", CIGRÉ Session, B2-101, Paris-France, 2008.

[7] J.S. Engelhardt, S.P. Basu, "Design, installation, and field experience with an overhead transmission dynamic line rating system", IEEE PES Transmission and Distribution Conference, pp. 366-370, Los AngelesUSA, 1996.

[8] J. Engelhardt, "Dynamic lyne rating system with real time tracking of conductor creep to establish the maximum allowable conductor loading as limited by clearance”, US Patent 2007/0200556.

[9] "Temperature and current measurement sensor for high voltage lines. SMT”, Technical Brochure, Arteche, 2009.

[10] C. Bernauer, H. Böhme, S. Grossmann, V. Hinrichsen, S. Kornhuber, S. Markalous, M. Muhr, T. Strehl, R. Teminova, "Temperature measurement on overhead transmission lines (OHTL) utilizing surface acoustic wave (SAW) sensors”, International Conference on Electricity Distribution CIRED, Vienna-Austria, 2007.

[11] T.O. Seppa, H.W. Adams, D.A. Douglass, N. Coad, A. Edris, P. Olivier, F.R. Thrash, "Use of on-line tension monitoring for real-time thermal ratings, ice loads and other environmental effects”, CIGRÉ Session, 22-102, Paris-France, 1998.

[12] T.O. Seppa, "Increasing transmission capacity by real time monitoring”, IEEE PES Winter Meeting, pp. 1208-11, 2002.

[13] I. Albizu, E. Fernandez, AJ Mazon, J Bengoechea, E Torres, Hardware and software architecture for overhead line rating monitoring, IEEE PowerTech Conference, Trondheim-Noruega, 2011.

[14] I. Albizu, E. Fernandez, AJ Mazon, M Bedialauneta, K Sagastabeitia, Overhead conductor monitoring system for the evaluation of the low sag behavior, IEEE PowerTech Conference, Trondheim-Noruega, 2011.

[15] I. Albizu, E. Fernandez, A.J. Mazon, J. Bengoechea, "Influence of the conductor temperature error on the overhead line ampacity monitoring systems”, IET Generation Transmission \& Distribution, Vol. 5, No. 4 2011.

[16] I. Albizu, A.J. Mazon, I. Zamora, "Flexible strain-tension calculation method for gap-type overhead conductors”, IEEE Transactions on Power Delivery, Vol. 24, No. 3, pp. 1529-1537, 2009.

[17] I. Albizu, A.J. Mazon, V. Valverde, G. Buigues, “Aspects to take into account in the application of mechanical calculation to high temperature low sag conductors”, IET Generation Transmission \& Distribution, Vol. 4, No. 5, pp. 631-640, 2010.

[18] I. Albizu, A.J. Mazon, E. Fernandez, "A method for the sag-tension calculation in electrical overhead lines", International Review of Electrical Engineering, Vol. 6, No. 3, pp. 1380-1389, 2011 